\title{
Parametricism as style: the relationship between methodology of scientific research programmes and parametric design
}

SIGRADI2018 TECHNOPOLITICAS xxii congresso da sociedade iberoamericana de gráfica digital 22th conference of the iberoamerican society of digital graphics $07|08| 09 \mid$ novembro|2018 iauusp | são carlos | spbr

\author{
Marcela Alves de Almeida \\ Universidade Federal de São João del-Rei | Brazil | marcela@ufsj.edu.br
}

Yasmim de Souza Nogueira

Universidade Federal de São João del-Rei | Brazil | yasmimnog13@gmail.com

\begin{abstract}
During the 1990s many architects, who dissociated from critical theory, were looking for new design methodologies that did not confine themselves as stylistic currents. One of these propractice movement is done by means of parametric design. Aiming to investigate the boundaries between methodology and style, this paper proposes to answer the question: does the parametric architecture constitute a new style, as Patrik Schumacher says? It reviews Heinrich Wölfflin concept of style in the contemporary context; it presents Imre Lakatos theory (methodology of scientific research programmes) and how Schumacher appropriates of it followed by a critical reflection on the limits of such appropriation.
\end{abstract}

Keywords: Parametric design; Style; Imre Lakatos; Patrik Schumacher.

\section{INTRODUÇÃO}

Desde o período de crítica e revisão do Movimento Moderno seguido pelas diversas experimentações do pós-modernismo que a teoria da arquitetura vem se afastando da noção de estilo arquitetônico e se aproximando de discussões relacionadas a outras disciplinas utilizando "conceitos mediadores - derivados de campos como a filosofia, a linguística, a psicologia e a antropologia - que ligam a arquitetura a outros campos sociais e, ao mesmo tempo, reivindicam (ou procuram reivindicar) um território próprio e exclusivo para a arquitetura" (Sykes, 2013, p.13). Desde então, viu-se a teoria e crítica da arquitetura ser organizada em diferentes correntes como aquelas da antologia teórica de Kate Nesbit (2006): o Pós-Modernismo, Estruturalismo, Pós-Estruturalismo, Desconstrutivismo, etc. Grande parte delas embasadas na filosofia continental.

Por outro lado, a partir da década de 1990 observa-se que muitos arquitetos, dissociados da teoria crítica, estavam em busca de novas metodologias de projeto (incluindo processos de representação) que não se configuraram por si só como correntes estilísticas. Tal postura aproxima a teoria da arquitetura muito mais da pesquisa em Design Thinking do que propriamente das investigações dos modelos - formais, plásticos e estéticos - aos quais determinada obra deve se submeter para estar caracterizada por um estilo. Por exemplo, o grupo NOX apoia-se no conceito de Autopoiese dos biólogos Humberto Maturana e Francisco Varela; Foreign Office Architects (FOA) desenvolve sua metodologia baseando-se no conceito de Filogênese; Greg Lynn com as formas Blobs. Sykes (2013) chama de pró-prática o movimento que busca colocar o foco da teoria na prática e na construção a partir do final da década de 1990, quando começaram a surgir propostas que substituíram as abstrações estáticas por processos dinâmicos de geração da forma, lançando novas bases para o processo de projeto influenciados pela tecnologia digital. Presenciase, então, ao final do século XX uma mudança nos paradigmas tanto formais quanto metodológicos.

Observa-se que estas propostas metodológicas estão associadas ao paradigma da informação e do pensamento sistêmico e para tanto necessitavam aproximar arquitetura e ciência, tal qual Patrik Schumacher (2008) faz ao recorrer à filosofia da ciência como base para sua conceituação de estilo, sem se contrapor a alguma definição específica de estilo e obra de arte já postulada por outros autores da teoria e crítica da arte e arquitetura. Schumacher se baseia nos escritos de Imre Lakatos (1978) sobre a metodologia de pesquisa científica, propondo estilo como programas de pesquisa. Neste contexto, o objetivo deste artigo é investigar uma resposta para a pergunta: a arquitetura realizada por meio da parametria se constitui como um novo estilo arquitetônico, tal qual afirma 0 arquiteto Patrik Schumacher (2008)?

Como metodologia o texto apresenta os conceitos para depois mobilizá-los em forma de reflexão crítica. O artigo se estrutura em quatro partes principais. A primeira expõe o conceito de estilo de Heinrich Wölfflin e propõe uma atualização, a fim de verificar a sua adequação à situação atual. A segunda parte, apresenta os programas de investigação científica de Imre Lakatos, tendo em vista que ele é a base na qual se apoia a afirmação de Schumacher de que o Parametricismo é um estilo arquitetônico. A terceira parte explora como Schumacher se apropria da teoria de Lakatos e reflete sobre os limites desta apropriação além de investigar relações entre arte e ciência revisando teóricos e filósofos que abordam o tema. 


\section{DO ESTILO AO DESENHO DE PROCESSO}

O conceito de estilo foi teorizado por diversos autores de história da arte e da arquitetura entre eles, Heinrich Wölfflin - escritor, filósofo, crítico e teórico da arte. Wölfflin conceituou estilo no início do século XX separando-o em três áreas principais que podem ser observadas na obras simultaneamente: I) estilo individual; II) estilo de nação, de escola ou de raça e III) estilo de época (Wölfflin, 2000).

O estilo individual pode ser compreendido como as características das obras que fazem parte não apenas da conjuntura espaço-temporal, mas também tratam do autor. De forma que Wölfflin declara que "[...] aos poucos entenderemos o complexo global das características pessoais de um estilo como a expressão de um certo temperamento" (Wölfflin, 2000, p. 9). Por outro lado, o estilo de nação, de escola ou de raça é a expressão de todo um sentimento nacional, consciência e valores considerada por ele espacial, em que "[...] o gosto formal entra em contato direto com elementos espirituais e morais, e a história da arte terá diante de si gratas tarefas, tão logo passe a abordar sistematicamente a questão da psicologia nacional da forma" (Wölfflin, 2000, p. 10). Já o estilo de época é a expressão dos tempos em que a obra está inserida e para Wölfflin se mescla ao estilo de raça.

Os três estilos identificados são parte de uma mesma definição, uma vez que o autor deixa claro que um se mescla ao outro e se fazem necessários no entendimento total da proposta de conceituação. Além disso, com esta tríade, "[...] pudemos ilustrar os objetivos de uma história da arte que concebe o estilo sobretudo como expressão, expressão de um espírito de uma época, de uma nação, bem como expressão de um temperamento individual" (Wölfflin, 2000, p. 13).

As proposições de Wölfflin são do início do século $X X$ e desde então, ocorreram mudanças profundas nas formas de produção artística, arquitetônica e científica, bem como nas relações sociais. A partir da Revolução Industrial, com 0 aumento dos processos de mecanização, da produção em massa e o crescimento das cidades aumentou-se a necessidade do controle e gerenciamento. Assim, por volta da década de 1950 vimos o surgimento da Cibernética como campo disciplinar que tem como propósito fazer com que os sistemas de comunicação se mantenham regulados e não se percam na entropia e no caos. Na teoria dos sistemas a relação entre as partes é fundamental para o equilíbrio e funcionamento do todo. Diferentemente da mecânica de Newton baseada nas propriedades físicas dos objetos e com modelos de sistemas fechados, a cibernética lida com o conceito de informação que "[...] não vem mediado pelo de substância, mas se baseia nas propriedades mutáveis do seu conjunto, isto é, a informação pode ser reproduzida (duplicada, copiada), destruída (apagada) ou repetida" (Giannetti, 2006, p.26).

Pode-se afirmar que a Arquitetura Paramétrica é fundamentalmente informacional e sistêmica. O sistema paramétrico é fundamentalmente topológico, baseado na tríade entrada, processamento e saída e deste modo, o arquiteto deixa de compor ou modelar a forma para desenhar sistemas e processos. Trata-se de um alto nível de abstração, já que todos os dados devem ser codificados numericamente para serem computados.

O desenho de processo, o elevado nível de abstração matemática e a contraposição às tendências subjetivas trazidas com os processos computacionais impulsionaram outro modo de conceber e pensar distintos dos anteriores, a saber o pensamento estilístico. Assim, necessitou-se buscar apoio em outras teorias para compreender tais mudanças nos processos estéticos:

Busca-se, por meio da formalização, uma contraposição às tendências subjetivistas, transcendentais ou existenciais das teorias estéticas inscritas na tradição kantianohegelianas. O fundamento de um sistema estético formal não tem por fim aprofundar a interpretação ou os juízos de valor, mas, ao centrar-se no próprio sistema da obra, ele ordena o significado dos elementos e dos signos por ela empregados. Toda obra de arte e, de um modo geral, toda expressão artística passam a ser consideradas como mensagem transmitida entre um indivíduo (ou um microgrupo) criador (artista/s), denominado emissor, e um indivíduo (ou grupo) receptor, por intermédio de um canal de transmissão (sistema de sensações visuais, auditivas, etc.) (Giannetti, 2006, p.37).

Frente a um novo sistema estético formal, é possível ensaiar uma atualização do conceito de estilo de Wölffllin, a fim de verificar se ele ainda é pertinente na atualidade.

I) estilo individual: a individualidade se tornou mais evidente na produção arquitetônica a partir do final do século passado quando os arquitetos passaram a buscar suas próprias referências em outros campos disciplinares (de modo individualizado e não mais em uma teoria da arquitetura que informa a prática) e estabelecer metodologias próprias. Nesta atualização deve-se entender a base do "estilo individual" como uma construção inter/transdisciplinar entre diferentes campos, e menos vinculado às subjetividades individuais (gênio criador).

II) estilo de nação, de escola ou de raça: ainda que seja possível perceber especificidades regionais na produção dos arquitetos, pode-se igualmente perceber que há uma forte influência da globalização. Tal processo está fundamentado no crescimento do ciberespaço e dos processos de comunicação em rede que não reconhecem os limites do território físico. O acesso à informação e à veiculação da produção arquitetônica mediada pelos veículos de comunicação colaboram para borrar fronteiras e para estabelecer uma "arquitetura globalizada" especialmente se levarmos em consideração a influência dos arquitetos do chamado "star system" na formação do imaginário de uma arquitetura globalizada. Os valores espaciais da contemporaneidade são cada vez mais globais.

III) Estilo de época: ao mesmo tempo em que se constata uma individualização por meio de metodologia própria, todos os arquitetos que trabalham digitalmente o fazem sob as condições deste meio que define (e limita) a estrutura na qual se trabalha. Ou seja, a influência mais determinante hoje não são as questões nacionais, de escola ou de raça, mas sim os condicionantes tecnológicos os quais se procura compreender, seguir ou superar. 
Nesta tentativa de estabelecer uma atualização do pensando de Wölflin, talvez o seu pensamento tenha se desestruturado na medida em que prevalece a interdisciplinaridade frente à individualidade, a globalização frente à nacionalidade e o estilo de época reside na base tecnológica e seu contexto social. Neste sentido, a aproximação do conceito de estilo com os programas de investigação científica pode apontar para um caminho mais coerente nas relações entre arquitetura, ciência e tecnologia.

\section{METODOLOGIA DOS PROGRAMAS DE INVESTIGAÇÃO CIENTÍFICA}

A metodologia científica teorizada por Lakatos envolve a produção de um programa de pesquisa científico baseado no falsificacionismo. No livro Falsificação e Metodologia dos Programas de Investigação Científica - publicado originalmente em 1978 - Lakatos faz uma revisão teórica de autores anteriores de diversas correntes enquanto justifica sua escolha por ampliar o falsificacionismo metodológico sofisticado de Popper. Para Popper, para que as teorias sejam científicas, elas precisam ser falsificadas. Lakatos se apropria disso e propõe um passo a mais com o programa de investigação científica que comporta uma série de teorias.

As teorias que integram um programa de investigação científica fazem parte de um sistema de inovação contínua e são caracterizados com núcleo firme de princípios que não pode ser quebrado. Deste modo, Lakatos propõe que o processo de pesquisa científico seja dividido metodologicamente em duas partes: caminhos a evitar - heurísticas negativas e os caminhos a seguir - heurísticas positivas. As heurísticas negativas determinam o núcleo firme e impedem que os questionamentos que levariam à refutação da teoria se orientem em direção ao núcleo central, deste modo criase um "cinturão de proteção" ao seu redor. Lakatos (1999) oferece como exemplo a teoria de Newton em que o núcleo firme é formado pelas três leis da dinâmica e a lei de gravitação universal. "Este 'núcleo' é 'irrefutável' pela decisão metodológica dos seus proponentes: as anomalias só devem conduzir a modificações na cintura 'protectora' de hipóteses auxiliares 'observacionais' e nas condições iniciais” (Lakatos, 1999, p. 56). Por outro lado, as heurísticas positivas representam os caminhos metodológicos que devem ser seguidos para a progressão daquela teoria ou do programa de pesquisa.

O programa de pesquisa lakatosiano leva em conta as teorias não como entidades separadas, mas como série em progressão. Desta forma, "O que se avaliará como científico ou não científico é uma sucessão de teorias e não uma dada teoria" (Lakatos, 1999, p. 54). Não há como considerar nenhuma teoria como científica separadamente, uma vez que para Lakatos o desenvolvimento da ciência se encontra na substituição de uma teoria vigente por outra rival ou posterior. A teoria substituinte deve explicar todos os fenômenos que a anterior se propunha; oferecer novos "fatos" ou fenômenos a serem observados e previstos e apresentar algum conteúdo adicional já "provado". Assim, há sempre uma ampliação de conhecimento ao longo do programa de pesquisa desenvolvido conforme o falsificacionismo metodológico sofisticado de Popper.

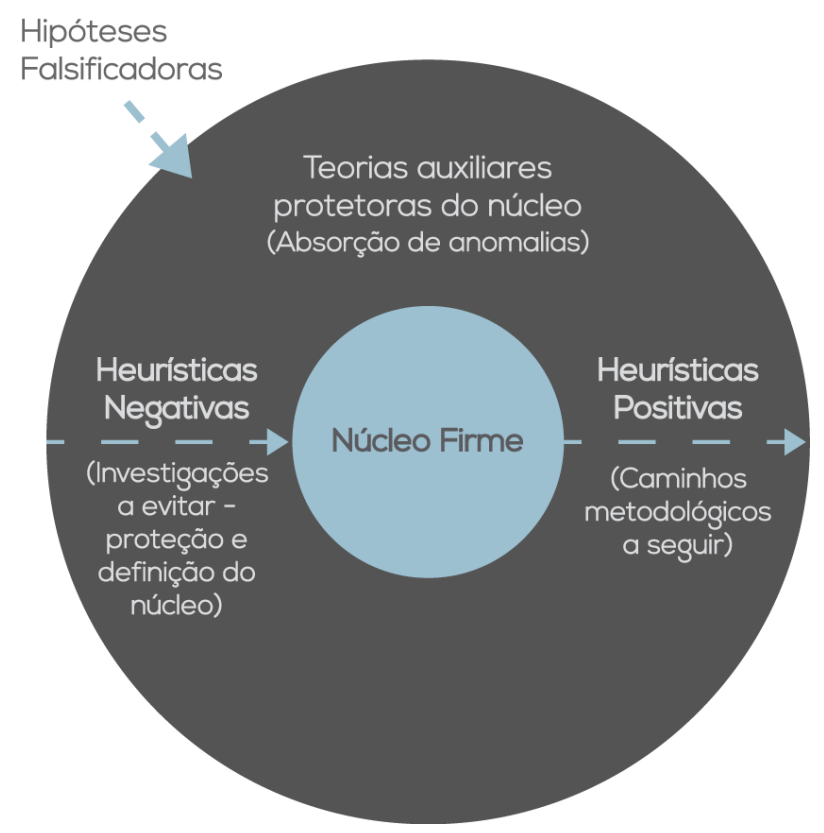

Figura 1: Diagrama composto com base na interpretação dos programas de pesquisa de Lakatos (Lakatos, 1999)

\section{O PARAMETRICISMO}

A definição de estilo proposta por Schumacher não se vincula a condicionantes como individualidade, espaçotemporalidade e expressão, mas se aproxima da teoria científica de Lakatos. Neste sentido, o conceito de estilo passa a ser entendido como um programa de investigação científica. Assim, Schumacher declara que os estilos são uma progressão uns dos outros e destaca como que a parametria avança em relação ao Modernismo que, para ele, foi o último estilo anterior ao Parametricismo. Para o arquiteto, todas as correntes entre ambos foram apenas episódios de transição. Ele considera que:

O estilo arquitetônico contemporâneo, que alcançou hegemonia generalizada dentro da arquitetura contemporânea vanguardista, pode ser melhor entendido como um programa de investigação baseado no paradigma paramétrico. Propomo-nos a chamar isso de estilo: Parametricismo (Schumacher, 2008).

De acordo com as afirmações de Schumacher é possível entender que a história da arte e da arquitetura podem ser vistas sob um ponto de vista evolutivo que culmina na contemporaneidade com a parametria. Os períodos se sucedem em constante regime de melhoria de intervenção no espaço assim como as teorias científicas se sucedem na tentativa de melhor explicar o mundo.

No texto de Schumacher não está declarado diretamente o que ele entende por núcleo firme, mas é possível depreender que se trata do conceito de campo que veio para substituir o conceito de espaço que fundou 0 Modernismo. Lefebvre também já havia destacado a relevância do espaço como estruturador do período Moderno ao afirmar que Sigfried Giedon foi o primeiro historiador que colocou o espaço no centro da história e não o "espírito dos tempos" ou o progresso tecnológico (Lefebvre, 2000). Deste modo, pode-se concluir que o programa de investigação do Modernismo tinha como núcleo firme o espaço enquanto no Parametricismo ele é o campo. 
Schumacher declara que "Arquitetura contemporânea visa a construir novas lógicas - a lógica de campos - que preparam-se para organizar e articular o novo nível de dinamismo e complexidade da sociedade contemporânea" (Schumacher, 2008). Ele declara ainda que os campos são como cheios preenchidos por fluídos, compara-o com enxames e ressalta a orientação, a deformação, a transformação e os vetores como características do campo.

$\mathrm{O}$ arquiteto não informa a fonte do conceito de campo, e quem o lê de modo desavisado pode lhe dar o crédito da formulação. No entanto, ao ler o artigo Condições de campo de Stan Allen (2013) publicado originalmente em 1999 no livro Points + Lines: Diagrams and Projects for the City pode-se constatar que Schumacher se apropria do conceito de Allen (2013) que define:

\begin{abstract}
Em termos gerais, uma condição de campo pode ser qualquer matriz formal ou espacial capaz de unificar diversos elementos, ao mesmo tempo respeitando a identidade de cada um deles. As configurações de campo são agregados frouxos, caracterizados pela porosidade e a interconectividade local. A forma e a extensão gerais são extremamente fluidas e menos importantes do que as relações internas das partes, que determinam o comportamento do campo. As condições de campo são fenômenos de baixo para cima, definidas não por esquemas geométricos gerais, e sim por conexões locais intrincadas. Intervalo, repetição e serialidade são conceitos fundamentais. A forma importa, mas não tanto as formas das coisas, e sim as formas entre as coisas (Allen, 2013, p.93).
\end{abstract}

Mais adiante, Allen aborda os conceitos de bandos, cardumes, enxames e multidões associando-os às condições de campo. Ele declara que "As condições de campo, oferecem uma abertura para que examine a dinâmica de usos, o comportamento das multidões e as geometrias complexas das massas em movimento" (Allen, 2013, p.100).

Observe que todas estas características estão associadas à ação e à informação e não diretamente à matéria. É por meio da ação que o arquiteto informa o processo de projeto que resultará em forma arquitetônica e/ou urbana. O foco se deslocou do objeto para o processo, da matéria para a ação. Este panorama já vinha sendo debatido teoricamente desde a década de 1990 com os conceitos de Transarquitetura de Marcos Novak, Arquitetura líquida de Ignasi Solà Morales, Arquitetura de limites difusos de Toy Ito (Almeida, 2011), entre outros, bem como as Condições de Campo de Stan Allen.

Deste modo, o conceito de campo é um termo que expressa e sintetiza a condição de sistema que a parametria traz como fundamento. Os sistemas paramétricos devem ser dinâmicos e comportar flexibilidade o suficiente para suportar transformações contínuas, para que sejam também continuamente informados: capacidade de receber nova informação, ser suficientemente plástico para se adaptar ao dinamismo das alterações dos valores de entrada, para trocar informações com o meio e materializá-las no objeto. O trabalho do arquiteto, nestes casos, passa a ser descrever sistemas formalmente. Para tanto é preciso identificar as partes que o compõe, estabelecer suas relações, organizá-lo espacialmente, definir a abertura para diferentes entradas e em função deles definir o processamento e as saídas.

Além do núcleo firme (campo), seguindo a metodologia dos programas de investigação científica, o parametricismo possui heurísticas positivas e negativas. Sobre elas o Schumacher declara que:

O programa/estilo consiste em regras metodológicas: alguns nos dizem os caminhos a serem evitados (heurísticas negativas), e outros que caminhos para perseguir (heurística positiva). As heurísticas negativas formulam críticas que impedem a recaída em velhos padrões que não são totalmente consistentes com o núcleo, e as heurísticas positivas oferecem princípios orientadores e técnicas preferenciais que permitem o trabalho a avançar em uma direção. As heurísticas que definem parametricismo estão totalmente refletidas nos tabus e dogmas da cultura do design contemporâneo vanguardista:

Heurísticas negativas: evitar tipologias familiares, evitar objetos platônicos / herméticos, evitar zonas/territórios bem definidos, evitar repetições, evitar linhas retas, evitar ângulos retos, evitar cantos e mais importante: não adicionar ou subtrair sem interarticulações elaboradas.

Heurísticas positivas: interarticulação, hibridismo, metamorfoses, desterritorialização, deformidade, iteração [repetição], uso de splines, NURBS, componentes generativos, script em vez de modelo (Schumacher, 2008).

As heurísticas propostas por Schumacher também se inserem dentro do pensamento sistêmico que permite que os arquitetos trabalhem diretamente com a informação que em um segundo momento resultará em espaço. A diferenciação contínua, correlações complexas, sistemas e subsistemas, só são possíveis dentro do programa do pensamento sistêmico.

Após investigar o texto de Schumacher frente ao de Lakatos, observa-se que o recorte que Schumacher faz da teoria de Lakatos é limitado, na medida em que se apropria apenas de alguns conceitos e os transpõe de uma forma pouco aprofundada, por exemplo, a heurística negativa. Schumacher considera apenas como os caminhos a serem evitados para que não se incorra em programas previamente utilizados em outros estilos anteriores. Para Lakatos o conceito de heurística negativa delimita o núcleo duro da teoria e o protege de refutações. É possível concluir que para Schumacher as heurísticas negativas apenas representam o oposto do que deve ser feito, portanto contrárias às heurísticas positivas. Em Lakatos ambas são complementares, uma vez que orientam a pesquisa para a comprovação, sem permitir que a teoria seja colocada em xeque com facilidade. Metodologicamente, as heurísticas negativas levam à criação de uma série de postulados auxiliares que explicam as anomalias de forma que estas não cheguem ao núcleo central. Schumacher não aborda hipóteses auxiliares ou a delimitação do núcleo rígido, portanto reduz as heurísticas negativas apenas a regras que não podem ser quebradas para que as obras não incorram em estilos passados. 


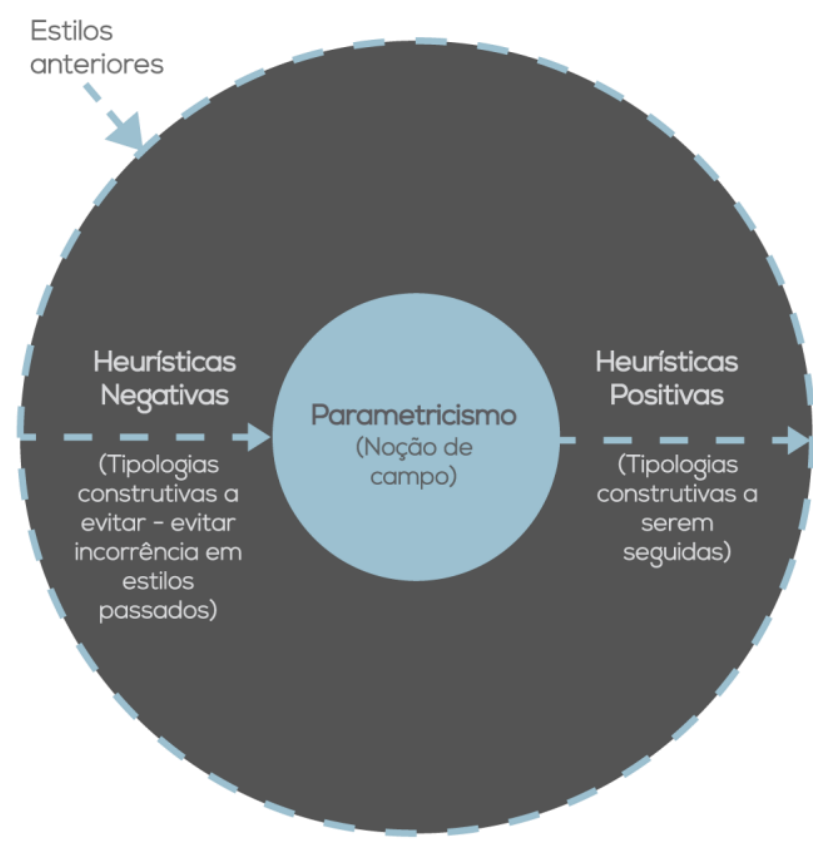

Figura 2: Diagrama composto com base na interpretação de como Schumacher se apropria da metodologia dos programas de investigação científica de Lakatos (Schumacher, 2008).

As mudanças nos processos de produção artística e projetual suscitam discussões a respeito da relação estreita entre arte e ciência. Para além de buscar paralelismos, é necessário entender o quanto a uma disciplina influi na outra. Para Paul Feyerabend, filósofo da ciência, arte e ciência se aproximam na medida em que ambas desenvolvem metodologias para a construção da verdade ou da realidade que são conduzidos pela própria forma de pensar. Deste modo, ambas são parte de uma construção social (as cited in Giannetti, 2006).

Feyerabend defende que as metodologias que estabelecem regras universais diretamente para a comprovação das teorias científicas de seus antecessores são contrárias às verdadeiras descobertas importantes para a ciência. Não há regras que se mantenham universais na produção científica (Chalmers, 1993). A posição de Feyerabend corrobora com o pensamento de Lakatos, já que Feyerabend, "é capaz de dar as boas-vindas a Lakatos como companheiro anarquista porque sua metodologia não fornece regras para teoria ou para a escolha de programas" (Chalmers, 1993, p.176).

A "falta de regras" é o que torna a proposta de Lakatos flexível para se adequar a diferentes momentos, absorvendo mudanças progressivas e se adaptando às diferentes construções sociais. Peter Weilbel também traça um paralelo entre arte e ciência a partir da metodologia. Para ele, "A ciência caracteriza-se por seu caráter metodológico, porém - como constata Weibel não se costuma considerar a arte como um método" (Giannetti, 2006, p.22). É justamente este esforço de aproximação entre arquitetura e ciência que Schumacher busca com sua teoria sobre o parametricismo como estilo. $\mathrm{O}$ arquiteto traz uma estrutura metodológica não rígida para os estilos arquitetônicos, uma vez que não estabelece regras universais que envolvem direta e particularmente os meios de investigação ou os processos de substituição de um estilo por outro.

\section{CONSIDERAÇÕES FINAIS}

O conceito de estilo de Wölfflin foi apresentado seguido de uma possibilidade de atualização frente à situação contemporânea que leva a uma quase descaracterização do conceito. Por isso a busca de Schumacher por uma nova conceituação de estilo aproximada da ciência lança um olhar renovado sobre a prática arquitetônica na medida em que se desvincula dos historiadores de arte e arquitetura.

Ao se aproximar de Lakatos, Schumacher não declara a qual definição de estilo ele contrapõe, mas estabelece uma clara conexão com o pensamento científico e coloca a ênfase na metodologia e não questões formais, plásticas ou compositivas. Ao analisar tal escolha utilizando a comparação que o próprio Schumacher faz em seu texto entre o Modernismo e Parametricismo, pode-se perceber que houve uma transição do conceito de espírito dos tempos, para espaço e finalmente para campo.

Ao se aproximar da metodologia de pesquisa científica lakatosiana para uma nova concepção de estilo entendese que os estilos se sucedem em um regime de evolução e melhoria contínua. A ciência se esforça para explicar fenômenos, mas em muitos casos já não é possível comparar os conceitos que os explicam. Por exemplo: os conceitos de massa em Newton e em Einstein se referem a diferentes estruturas do cosmos, mecanicista para os postulados newtonianos e relativística para as teorias de Einstein (Cherman \& Mendonça, 2010). Da mesma forma, não apenas houve mudanças nas relações plásticas, formais e compositivas dos estilos anteriores para 0 parametricismo, mas também a mudança de uma concepção de espaço para uma noção de campo. Assim, não há como comparar ontologicamente o parametricismo com estilos anteriores sob uma ótica de melhoria evolutiva já que não se referem ao mesmo universo projetual.

Com a inauguração do pensamento sistêmico, a noção de campo e a utilização da tecnologia digital, os estilos que sucederão o parametricismo poderão ser analisados sob uma ótica de melhoria contínua na medida que se mantenham no mesmo universo projetual ou, como Schumacher (2009) observa, o avanço contínuo do parametricismo só pode ocorrer mediante a apropriação das técnicas computacionais de scripting e modelagem paramétrica.

\section{AGRADECIMENTOS}

Agradecemos a colaboração do professor Dr. Gustavo Leal Toledo da Universidade Federal de São João delRei.

\section{REFERÊNCIAS}

Allen, S. (2013) Condições de campo. In Sykes, K. O campo ampliado da arquitetura: antologia teórica 1993-2009 (pp.92103). São Paulo: Cosac Naify. 
Almeida, M. (2011). O desejo de desmaterialização da arquitetura: a plasticidade como processo. Risco,14, 63-71.

Chalmers, A. F. (1993). O que é a ciência afinal? São Paulo: Brasiliense.

Cherman, A., Mendonça, B. R. (2010). Por que as coisas caem? Uma história da gravidade. Rio de Janeiro: Zahar.

Giannetti, C. (2006). Estética Digital: sintopia da arte, a ciência e a tecnologia. Belo Horizonte: C/ Arte.

Kolarevic, B. (2003). Architecture in the digital age: design and manufacturing. New York: Spon Press.

Lakatos, I. (1989). La metodología de los programas de investigación científica. Madrid: Alianza Editorial

Lakatos, I. (1999). Falsificação e Metodologia dos Programas de Investigação Científica. Lisboa: Edições 70.

Lefebvre, H. (2000). La production de l'espace (4th ed.). Paris: ÉditionsAnthropos.
Nesbitt, K. (2008). Uma nova agenda para a arquitetura: Antologia teórica 1965-1995. São Paulo: Cosac Naify.

Schumacher, P (2008). Parametricism as Style: Parametricist Manifesto. London. Recuperado em 20 junho, 2018 de http://www.patrikschumacher.com/Texts/Parametricism\%20a s\%20Style.htm

Schumacher, P. (2009). Parametricism. A New Global Style for Architecture and Urban Design. In Carpo, M. The digital turn in Architecture (pp.241-257). United Kingdon: John Willey \& Sons.

Sykes, K. (2013). O campo ampliado da arquitetura: antologia teórica 1993-2009. São Paulo: Cosac Naify.

Wölfflin, H. (2000). Conceitos fundamentais da história da arte: o problema da evolução dos estilos na arte mais recente (4th ed.). São Paulo: Martin Fontes. 